\title{
A atenção básica na construção da saúde
}

\section{Primary care at health construction}

Juan Stuardo Yazlle Rocha ${ }^{3}$

M aria do Carmo Gullaci Guimarães Caccia-Bava ${ }^{4}$

O trabal ho “Programa Saúde da Família no Brasil: uma agenda incompleta?", de autoria de $\mathrm{M}$ aria de Fátima Souza e Edgard Merchán Hamann, propõe-sea realizar uma análise longitudinal da experiência brasileira nessa área desde a perspectiva de considerar o mesmo um projeto de reorganização da atenção básica. Discutem o significado do PSF diante da realidade de serviços de atenção básica ou de atenção primária à saúde, destacando o significado de implementar um novo modelo e os principais marcos oficiais do processo de desenvolvimento dessa estratégia. Entre avanços e desafios, apontam para as necessidades mais urgentes em termos de incorporação tecnológica, formação da força de trabalho, estabelecimento de novos mecanismos e pactos em torno do financiamento da atenção básica e encaminhamento de novas estratégias e tecnologias nos processos de monitoramento e avaliação. Alguns pontos são destacados, como a questão da expansão da cobertura em grandes centros urbanos, a co-responsabilidade do financiamento da atenção básica e a política de capacitação, formação e educação permanente para o PSF.

\section{Algumas considerações}

0 título do artigo sugere que os autores atribuiriam ou focariam na questão da agenda incompleta a razão das dificuldades ou problemas da estrutura e organização dos serviços de atenção básica no país. Eles tratam de várias questões outras e também de várias agendas: das agendas oficiais (de 
municípios, estados e União), das agendas dos atores sociais - movimento sanitário, a tecnocracia da saúde, grupos acadêmicos da saúde coletiva, entre outros. O SUS - mais que a Saúde Coletiva - é resultante da somatória de forças sociais, como as referidas antes, muitas vezes assíncronas, divergenteseatéconflitantes. Tecnicamenteéfácil encontrar textos especializados - como o de Starfield, para ficar num dos autores citados - que sistematizam e apresentam um todo organizado e coerente acerca da aten ção primária e saúde da família e que constituem importantes referenciais para a implantação de serviços e projetos. Como é sabido, não há prática sem uma teoria que a oriente - todavia, desenvolver um projeto ou programa não é uma tarefa técnica apenas (domínio dos conteúdosereunião e aplicação dos recursos necessários), mas principalmentepolítica- conseguir queos "outros" queiram o nosso projeto ou proposta (ou o adotem ou adiram a ele/ela) como se deles fosse. Esta é a principal dificuldade, nem sempresuficientemente compreendida, que marca a agenda da construção do SUS. O SU Sse desenvolveeavança na medida em que os atores sociais (técnicos, políticos, acadêmicos) coincidem ou convergem em cada passo ou etapa. Daí também observarmos, por vezes, aparentes "atrasos" ou descompassos no processo de construção do SUS. Tal éa explicação, certamente, para o fato quea Conferência deAlmaAta enunciou as diretrizes da atenção primária em 1978 - de conhecimento das áreas acadêmicas e objeto do desejo de muitos militantes da saúde - e apenas em 1994, dezesseis anos depois, teve início a implantação do PSF como política pública - descontados al guns esforços restritos, citados pelos autores, no estado do Ceará, na cidade de São Paulo e outros lugares. Construir o consenso em torno da necessidade de mudar o modelo de assistência, aceitar que deveria haver uma porta de entrada acessível para uma população de referência conhecida, com seus problemas de saúde conhecidos e avaliados de forma a fundamentar um planejamento e programação deaçõesé, afinal, o passo mais importantepara a transformação das práticas na assistência à saúde da população. Aceitos os preceitos, temos então a agenda - e, como já foi dito, o homem só se propõe problemas que (quando) ele pode resolver.

Uma segunda consideração éque a aten ção básica e a saúde da família não podem descolar-se do processo de desenvolvimento do SUS, pois não possuem autonomia para tanto. Queremos dizer que, antes da descentralização, da solução dos repasses fundo a fundo, do desenvolvimento dos modelos degestão e definição das atribuiç̧ões assistenciais de responsabilidade dos municípios, que configuram o cenário de definição da área da saúde na esfera municipal, dificilmente haveria outros avanços - fossem focais ou parciais. Cabe lembrar que, tendo em vista a autonomia dos entes federados que conformam o Brasil, a adesão a modelos ou projetos passa em muito pela construção deuma hegemonia no pensar e fazer saúde - tarefa que de forma nenhuma pode ser subestimada. Outra vez, devemos reconhecer que antes destas questões estarem estabelecidas, houve cidades e municípios, com parcerias acadêmicas ou não, que de forma pioneira iniciaram projetos de construção de um novo modelo de atenção primária à saúde, inspirados nos conhecimentos e experiências de outros países, principalmente. M as foi somente após a superação dessas etapas que se abriu a possibilidade deestruturar políticas de atenção básica que requerem, entreoutras coisas, o devido suporteinstitucional, como a criação do DAB/SAS/M S. Isto posto, a agenda do desenvolvimento da atenção básica e saúde da família passou a ser exigência do desenvolvimento do Sistema Único de Saúde como um todo e os primeiros produtos viriam no bojo da NOB 96 - queinstituiu a descentral ização (municipalização) e os modelos de gestão dos sistemas municipais de saúde, definiu os repasses fundo a fundo de recursos per capita (como citado) ea suspensão do pagamento de atendimentos básicos em serviços regionais de saúde. Criou, pois, as condições para a proposição sistematizada da organização da atenção básica - Portaria no 3.925 de 13/11/ 1998 e M anual de Organização da AB no SUS. Entretanto, a consolidação deste avanço requeria estabelecer a definição de atribuições entre serviços municipais (primordialmente de atenção básica) e os de caráter regional, divisão de tarefas na saúde entre órgãos municipais e estaduais, definição que viria com a N OAS 2001 eN OAS2002, queexplicitaram atribuições na atenção básica, média e alta complexidade, passando a primeira a ser atribuição precípua dos governos municipais. Como não chegam a trezentos os municípios brasileiros com mais de cem mil habitantes, para a imensa maioria dos municípios, a saúde se resume aos serviços ou sistema municipal de saúde, isto é, a atenção primária. Os níveis assistenciais - a atenção básica, a média e alta complexidade - estarão presentes em poucos municípios que, no entanto, concentram a maior parte da população do país. Ali se coloca a questão da articulação entre os diferentes níveis assistenciais e 0 avanço do SUS passa a requerer a superação da questão local-regional ou atenção básica versus especialidades - ea regionalização (solidária, se preferir a adjetivação) se torna a questão do momento. Não é de se estranhar, portanto, que 
com diferença de apenas dois dias, em março de 2006, são editadas duas novas Portarias: a 648 de 28/03/2006 que define a Política Nacional de Atenção Básica, estabelecendo a revisão de diretrizes e normas para a organização da A tenção Básica para o Programa Saúdeda Família (PSF) eo Programa Agente Comunitários de Saúde (PACS), onde reafirma 0 conceito da atenção básica e explicita que deva ser desenvolvida por meio do exercício de práticas gerenciais e sanitárias democráticas e participativas, sob forma de trabalho em equipe, dirigidas a populações de territórios bem delimitados. Podemos concordar facilmente com a citação de Campos et al. ${ }^{1}$, que assinala o caráter original einédito do modelo brasileiro de PSF devido ao trabalho multiprofissional e em equipe - embora seja muito mais original e inovadora a concepção da saúde a partir da PT 699 de 30/03/2006 que fixou as Diretrizes O peracionais do Pacto pela Vida e de Gestão. M ais do que a criação do Teto Financeiro do Bloco da Atenção Básica - soma das partes fixa evariável do Piso da Atenção Básica - o Pacto de Gestão conduz os municípios a dialogarem entre si ecom o Estado, reconhecendo as dificuldades e possibilidades de cada um para, a partir daí, integrar ações e compartir recursos mediante compromisso público, apreciado e aprovado pelos respectivos Conselhos de Saúde, resultando nos Termos de Compromisso de Gestão dos municípios e estados - sem necessidade de mecanismos legais do tipo convênios ou contratos, mas de verdadeiros pactos políticos pela saúde.

Esses espaços de interlocução entre as três esferas de gestão abrem a possibilidade de se articular medidas de superação para o desfinanciamento sistemático que o SUS vem enfrentando desde a década de noventa, com desdobramentos para o financiamento da atenção básica e saúde da família. Vale lembrar que logo no seu início deixaram de ser destinados ao setor saúde os $30 \%$ do orçamento da Seguridade Social, a fonte de receita previdenciária, eaCPM F vai deadicional a substitutiva, passando pelo desenho final da Emenda Constitucional 29, quepermitiu clara retração da participação da esfera federal em relação às demais. Sua não regulamentação levou, só no ano de 2005, a que dezessete estados e 430 municípios deixassem de investir o mínimo legal exigido para a saúde. Seu descumprimento pela União e estados significou, de 2000 a 2004, uma perda de R $\$ 7,2$ bilhões, de acordo com $M$ endes ${ }^{2}$. Em outras palavras, não se pode esperar que a atenção básica e o PSF se financiem frente ao desfinanciamento do SUS.

Uma terceira consideração diz respeito à necessidade de expansão da cobertura nos grandes cen- tros urbanos e às dificuldades apontadas para realizar tal tarefa2-4: a existência e predomínio de modelos tradicionais de atenção básica e de programas verticalizados que dificultam a superação do modelo assistencial vigente ${ }^{5}$ - centrado na assistência a doenças, à demanda e calcado no trio mé dicos-equipamentos-medicamentos - cenário onde se desenrolam os embates políticos partidários, os interesses corporativos mais o subfinanciamento geral da assistência. A verdade éque, onde foram feitas tentativas de implantar serviços de atenção básica baseados no PSF e PACS, não foi possível demonstrar - à população usuária e aos gestores responsáveis - a vantagem marginal do modelo PSF quando comparado aos sistemas tradicionais - ou houveligeira vantagem, visível para os ol hos técnicos e menos perceptível para os usuários $^{6}$ - vantagem esta quanto à porta de entrada ao sistema e ao vínculo com o profissional, mas pouco aceita quanto à acessibilidade. Ou seja, se o modelo não oferece vantagens do lado financeiro (o subsídio federal é insuficiente) mas ao contrário demanda mais recursos, também não consegue seduzir a maioria da população que não enxerga nele um modelo superior ao tradicional.

Viabilizar a assistência integral, humanizada e resolutiva requer um processo de trabalho em saúde articulado intra e inter equipes de saúde, na perspectiva da construção das linhas de cuidado. Nesse sentido, a Educação Permanente (EP) pode ser um forte disparador para a construção desse projeto técnico, ético e político, ao superar a mera aquisição cumulativa de informações por parte do trabalhador para problematizar e transformar, de forma sistemática, o processo e a organização do trabalho em saúde.

No que diz respeito à formação dos futuros profissionais, há que se destacar al gumas políticas indutoras de mudanças realizadas de forma articulada pelos ministérios da Saúde e da Educação, como o Pró-Saúdee, mais recentemente, o Pet Saúde, que valorizam os saberes existentes na rede assistencial e permitem incorporar à formação acadêmica a lógica do SUS.

Finalmente, concordamos com Campos ${ }^{1}$ que no debate com Conill ${ }^{7}$ reconhece que ainda há " 'desafios' teóricos e operacionais - problemas de extensão, de intensidade e de sustentabilidade - à implementação de uma rede de atenção básica no Brasil".

Nossa proposta aqui foi procurar a racionalidade (ou lógica) que presidiu a definição de sucessivos passos na construção do SUS - compondo implicitamente uma agenda orientada à solução 
ou encaminhamento dos problemas da saúde em geral e da atenção básica em particular. Como seria deesperar, ela não seguea racionalidadetécnica da construção de um sistema de atenção básica, mas o caminho do possível, percurso técnico e político para sustentar o desenvolvimento do Sistema Ú nico de Saúde.

\section{Referências}

1. Campos GWS. Suficiências e insuficiências da política para a Atenção Básica no Brasil. Cad Saude Publica 2008; 24(Supl. 1):S17-S19.

2. M endes A. Financiamento, gasto e gestão do SU S: a gestão descentralizada semiplena e plena do sistema municipal do Estado de São Paulo (1995-2001) [tese]. Campinas (SP): Instituto de Economia, Universidade Estadual de Campinas; 2005.

3. Viana ALD, Rocha JSY, Elias PE, I bañez N, Bousquat A. Atenção Básica e dinâmica urbana nos grandes municípios paulistas, Brasil. Cad Saude Publica 2008; 24:579-590.

4. Ibañez N, Rocha JSY, Castro PC, Ribeiro MCSA, Forster AC, Novaes MHD, Viana ALD. Avaliação do desempenho da atenção básica no Estado de São Paulo. Cien Saude Colet 2006; 11(3):683-704.

5. Viana ALD, Rocha JSY, Elias PE, Ibañez N, Novaes MHD. Modelos de Atenção Básica nos grandes municípios paulistas: efetividade, eficácia, sustentabilidade e governabilidade. Cien Saude Colet 2006; 11(3):577-606.

6. Elias PEM, Ferreira CW, Alves M CG, Cohn A, Kishima V, Escrivão A, Gomes A, Bousquat A. Atenção Básica em Saúde: comparação entre PSF e UBS por estrato de exclusão social no município de São PauIo. Cien Saude Colet 2006; 11(3):633-642.

7. Conill EM. Ensaio histórico-conceitual sobre a Atenção Primária à Saúde: desafios para a organização de serviços básicos e da Estratégia Saúde da Família em centros urbanos no Brasil. Cad Saude Publica 2008; 24(Supl. 1):S7-S16. 